\title{
Who is leading China's family planning policy discourse in Weibo? A social media text mining analysis
}

\author{
Wen Deng $^{1}$ (1) | Jia-Huey Hsu ${ }^{2}$ (1) | Karl Löfgren ${ }^{3}$ (B) | \\ Wonhyuk $\mathrm{Cho}^{3}$
}

${ }^{1}$ College of Public Administration, Huazhong University of Science and Technology, Wuhan, Hubei, China

${ }^{2}$ Department of International Business, Tamkang University, Taipei, Taiwan

${ }^{3}$ Wellington School of Business and Government, Victoria University of Wellington, Wellington, New Zealand

\section{Correspondence}

Wonhyuk Cho, Wellington School of Business and Government, Victoria University of Wellington, Wellington 6011, New Zealand.

Email: wonhyuk.cho@vuw.ac.nz

\section{Funding information}

Fundamental Research Funds for the Central Universities, Grant/Award Number: 2015AE002

\begin{abstract}
The advent of digital social media in China has altered our understanding of who sets the policy agenda and forms public opinion. Using text mining analysis of more than 74,000 Weibo user comments (over 4 million words) on 6 years' worth of The People's Daily media coverage, this study investigates social media interactions on family planning policy issues between the state-run news media and individual users in China. Our analysis demonstrates that Weibo postings about the topic by government-run news networks and comments by the general public are affecting each other, but also presenting partially reverse or bottom-up agenda-setting effects. Through latent dirichlet allocation (LDA) modeling, we identified major latent topic sets (women's right to work, family culture/ tradition, law/regulation, and social welfare/wellbeing) and found that Weibo users' main concerns on China's family planning have changed over time. We also found that gender differences affect the topics of commenters.
\end{abstract}

\section{KE Y WORDS}

agenda-setting, China, public opinion, social media, three-child policy, Weibo

\section{INTRODUCTION}

In any democratic polity, the government's responsiveness to the public's policy preferences is an enduring issue (Barberá et al., 2019; Guntermann \& Persson, 2021; Im et al., 2013; Löfgren et al., 2018). Even though China is a one-party state, the lack of public engagement in policy issues, such as family planning programs, may still affect citizen support, subsequently affecting the legitimacy of the government policy (Wang \& Chen, 2016). Equally, 
digital media facilitates rapid dissemination of information and ideas, which in turn allows governments to quickly assess the flows of public discourse and use social media platforms to manage public opinions and push desired policy agendas (Chan, 2007).

The academic literature has for a long time explored the nature of interactions between the public, mass media, and government authorities (Barberá et al., 2019; Im et al., 2014). However, the rapid expansion of the Internet and social media has challenged existing understandings of policy agenda-setting (Grzywińska \& Batorski, 2016; Li et al., 2003). Whereas conventional agenda-setting theory allocates a central role to mass media's influence on public opinion, the interactive and open nature of social media challenges this theory (Vargo \& Guo, 2017), and changes the focus from what issues the "media tell people" to think about to those "people tell the media" to write about (Chaffee \& Metzger, 2001, p. 375; McCombs, 2018). Studies on these "reverse agenda-setting effects" show that, in social media environments, the public is no longer an insignificant and passive actor in top-down agenda-setting processes, but in fact an important influencer through bottom-up agenda setting (Grzywińska \& Batorski, 2016).

Meanwhile, research on social media and policy agenda setting in China is still embryonic (Lin \& Zhang, 2020). Scholars suggest that the country's state-run media's influence on public opinion has changed in recent years reflecting the increased use of social media platforms. Among these, Weibo is probably the most renowned example, with more than a half-billion active users. Unsurprisingly, this development has naturally changed the patterns of agendasetting. Sun and Zhang (2015) argue that Chinese traditional media have visibly upheld their ideological stance in the new media environment, while the role of state-run media has transitioned, due to the so-called "reversed agenda-setting" phenomenon (Jiang, 2014).

However, there have been conflicting academic views on this transition. Some scholars argue that the traditional gate-keeping role of Chinese media has declined as social media platforms allow bidirectional flows of information and opinion. Others suggest that Weibo is, in fact, more effectively leveraging the Chinese government policy agenda in public discourse as new media has proven more effective in the dissemination of information, and is easier to monitor, censor, and respond to in a targeted fashion. Nevertheless, much research on Chinese social media remains insular, focusing on, for example, dialectical discussions of political scandals, individual cases, or mass incidents (Fu et al., 2013; Hassid, 2012; Meng et al., 2017; Nip \& Fu, 2016). The big data resources of Chinese social media have received relatively less attention, even though they represent a unique share of the global Internet (Jiang \& Fu, 2018). This limits international scholarship on the subject, as there is little research to build upon.

Informed by recent developments in "social media agenda-setting" theory (Feezell, 2018), this article explores the interaction between Weibo users and the Chinese stateowned media, represented by The People's Daily, in the social media environment. We examine the bottom-up (reverse) agenda-setting effects in the Chinese family planning policy discourse.

We selected Chinese family planning policy as our subject of analysis for several reasons. Our research questions required a policy area which the general public is aware of and has some knowledge about. Chinese citizens are generally well-informed about the family planning policy, as it has for decades now had a direct impact on all families (regardless of demographics or region). Second, the family planning program is a highly visible policy issue, generating lots of top trending posts on Chinese social media platforms. Finally, the government has strictly enforced family planning policy, therefore related issues were regarded as sensitive, controversial, and potentially incendiary subjects (Fu et al., 2013). The transformation emerged when national population census revealed prolonged low fertility, elevated sex ratios, and rapid aging. Established population policies began to relax, and related discussions were allowed and even encouraged (Cai, 2013). Currently, family planning policy is relatively less charged, allowing for text-mining data collection. 
Our main research questions are: Does the Chinese general public's family planning policy agenda, as represented by individual Weibo users, influence The People's Daily's media coverage on the social media platform (and vice versa)? How does the state-run media report the series of changes in family planning policy on the Weibo platform? and Are there gender differences among Weibo users in family planning agenda over time?

\section{LITERATURE REVIEW}

\section{Agenda-setting in the age of social media}

There is a long and rich history of applying agenda-setting theory in the study of mass communication/media and the formation of public opinion (Guo \& McCombs, 2015; McCombs \& Shaw, 1972; Weaver et al., 2004). Traditional agenda-setting theory suggests that mass media influences public opinion by leading attention, perceiving salience, and determining issues (Watson, 2008); it influences which issues are considered important by the public (Luo, 2014). Traditional media holds a monopoly on creating content (Lippmann, 1946) and acts as a gatekeeper for the public's mind (Janowitz, 1975).

The rapid expansion of the Internet and social media platforms has generated new research avenues regarding the role of agenda-setting in digital environments (Feeney \& Porumbescu, 2020; Feezell, 2018; Li et al., 2003). Social media's open and interactive properties offer a direct and embedded "user-to-user information exchange" (Feezell, 2018; Honey \& Herring, 2009, p. 1). Shaw $(2004,2006)$ suggest that traditional mass media is characterized by vertical communication flows (and vertical agenda-setting processes), whereas modern Internet media is driven by horizontal communication flows (and consequently horizontal agenda-setting processes), generating new forms of social interaction and promoting deliberation (Aragón et al., 2017; Cho \& Melisa, 2021). Internet and social media enable individual citizens to put forward divergent agendas, challenging the control of mass media or government information outlets (Allen et al., 2020; Ho \& Cho, 2017; Vargo \& Guo, 2017).

New research exploring the reversed roles of senders and recipients in social media has emerged (Groshek \& Groshek, 2013). This phenomenon of bottom-up or reverse agendasetting is promoted by individuals' feedback to media content, giving the public more autonomy to influence public affairs and requiring journalists to pay more attention to viral social media conversations and relay the opinion streams of the public (Fu et al., 2013; Luo, 2014). Meanwhile, social media provides a space for political commentary (Stockmann \& Luo, 2015). People may voice specific preferences, and since the government cannot learn these preferences via formal channels, officials look to the Internet to find a more comprehensive array of opinions (Meng et al., 2017). As a result, the public's role in the agendasetting process changes from passive, insignificant player to heavily influential actor (McCombs, 2018).

Most social media and agenda-setting research has been conducted in the context of Western democracies, specifically on Twitter or Facebooks users, such as those focused on US politicians' adoption of these platforms to leverage their political agendas (Yang et al., 2016) or the technology firms' active involvement in shaping political communications in the electoral campaigns (Kreiss \& McGregor, 2018). With respect to reversed agenda-setting, Barberá et al. (2019) concluded that US legislators tended to "follow, not lead" the discussion of policy issues on Twitter, and were more likely to respond to their political supporters than to the general public. Still, existing studies leave unanswered questions about this 
reversed form of bottom-up agenda-setting on social media in a "non-west, state-regulated environment” (Guo, 2019, p. 2463; Kim et al., 2019, 2020; Sagarik et al., 2018).

\section{State media and social media in China}

The number of Chinese Internet users has reached 940 million (67\% of the total population), including no fewer than 859 million social media users, upending traditional media's news distribution and coverage of social issues (Yang et al., 2016). Some scholars suggest that the Chinese media's gatekeeper role has been overturned (Conway et al., 2015), while others respond that the Chinese government news monopoly has just shifted (Wu et al., 2013) to focus on guiding public opinion through a "more indirect, flexible and subtle way" (Chan, 2007; King et al., 2013).

The Chinese government has presented a strategy of "media convergence" (Li et al., 2003, p. 171), pushing traditional media to establish a visible presence for upholding ideological positions on the new digital media platforms (Sun \& Zhang, 2015). While a handful of studies have reported interactions between online public opinion and Chinese mass media, such as newspaper or television (Conway et al., 2015; Groshek \& Groshek, 2013), most have not explored the tectonic shifts in China's underlying media landscape (Hassid \& Sun, 2015), which make it more difficult to empirically test new forms of traditional media. The social media accounts of traditional media function as the main channels of propaganda for government officials and as windows through which the public may post anonymous comments (Hassid, 2015; Meng et al., 2017). Their dual attributes of authority and interactivity make them nimble and subtle communication portals between the government and the public.

Weibo is the most-used Chinese social media platform, with a half-billion users in mainland China alone. The open, anonymous, and interactive social network platform has offered prominent digital space for policy discourse ( $\mathrm{Gu}, 2014$; Hutchinson, 2021), allowing users to post stories and comments immediately after or during news events and lead public opinions on a number of policy issues. For instance, Wu et al. (2013) observed the influence of Weibo on agenda-setting in China following a disastrous railway accident: it played a decisive role in setting mainstream media's agenda and narratives in reporting this accident, and raised politically sensitive issues that conventional media downplayed. Some reports suggest that the public opinion expressed through Chinese social media has the potential to act as a countervailing force to the governments' control over information flow, while others argue that individual Weibo users are increasingly monitoring issues such as corruption, pollution, and food safety in China (Gu, 2014; Qin et al., 2017).

Nan (2003, p. 6-7) describes two partially distinct but overlapping spaces for public opinion formation in China: the first is the traditional "media space" facilitated by the government-running mainstream media, and the second is the "verbal space," molded by public word of mouth. With an increasing number of citizens participating in social media discussions, online opinions pose a challenge to the traditional agenda-setting power of the Chinese state-run media (Luo, 2014; Wang, 2015). Meanwhile, Weibo has expanded this digital "verbal space," providing the possibility of a "partial reversed agenda-setting" phenomenon in China's digital media environment (Jiang, 2014).

$\mathrm{Gu}$ (2014, p. 72) suggests that Weibo enjoys much more freedom from government censorship, and that social media is regarded as "a bridge of mutual communication" between the Chinese government and its citizens. Chinese journalists in mainstream media also report differently-while still operating as in the past, they also keep an eye on viral social media opinions on various policy issues, and "gain insight into the tone of online discussions" (Luo, 2014, p. 1306). For example, Z. Chen et al. (2019) studied the 
dissemination of Chinese nationalism issues on social media, and found a bottom-up pattern. Furthermore, Su and Xiao (2020) revealed that WeChat discussions happened quite independently from party newspaper's agendas, suggesting that government mouthpieces may not work in digital spaces.

Other scholars argue that the Chinese government does in fact use social media as an effective propaganda channel (Qin et al., 2017). Traditional media outlets have set up social media accounts to more effectively disseminate news agenda-Chinese newspapers' Weibo accounts are also considered to be more credible, and more neutral, than the traditional printed equivalents (Xu et al., 2013). Furthermore, the ubiquity of social media supports unprecedented opportunities for the government to monitor individual citizens' political opinions in real-time (Conover et al., 2011). Nip and Fu (2016) found that though people can use social media to initiate agendas, they still rely on media organizations to spread information. As such, social media platforms can nudge citizens' views towards the direction of mainstream media, and Weibo may very well serve as propaganda for the current Chinese political system (Gu, 2014; Roberts et al., 2002). This type of engagement may function as a safety valve and gain policy legitimacy (Hassid, 2012, 2015; Meng et al., 2017). Contrary to its Western social media counterparts, the Weibo platform offers users only "partially-allowed freedom"; the actual status of state internet censorship is ambivalent (Gu, 2014).

While some research has studied social media as a completely separate form (Wu et al., 2013), others focus on traditional newspapers' social media visibility (Xu et al., 2013). This article's focus is on the Weibo account of the state-owned The People's Daily, which has the largest viewership and is likely the most influential among traditional media actors on Weibo. The People's Daily's social media account, established in 2012, reached 123,000 postings and at least 122 million followers by early 2021. Its special status as the government-run official (national) media creates a rather exclusive role, directly influencing government national agenda-setting in other media outlets (Xu et al., 2013) and serving as the prime voice of the Chinese Communist Party's policy agenda (Luo, 2014).

\section{Family planning policy discourse in China}

The Chinese one-child policy emerged in the 1970s, as the initiative to control population to alleviate severe national poverty (Hesketh \& Zhu, 1997). When this strict family planning program was introduced (Huang, 2017), few media outlets existed in China, and the mainstream media was basically the official "transmission belt" of the Chinese Communist Party, and most Chinese citizens succumbed to a "managed" information hierarchy (Gu, 2014; Pan, 2000).

The long-standing one-child policy resulted in a dramatic decline in the country's fertility rates, leading to a more inverted population triangle. Undesired policy outcomes included a reduction in the active workforce and a gender imbalance, which may now risk China's longterm economic and demographic stability (Ding \& Zhang, 2014; Gong et al., 2016).

In 2013, the National Health and Population Planning Commission announced the "selective two-child" policy, specifying that parents from a single-child family were entitled to have a second child. In 2016, the one-child policy was formally replaced by a universal two-child policy (Zeng et al., 2017). In 2021, the Chinese authorities announced that they will allow all married couples to have up to three children, which came over only five years after the earlier two-child policy. Relaxing the policy sparked public discussion in the growing social media realm. New capabilities to tailor public media consumption to each individual's interests disrupted the traditional state media's monopoly on shaping public cognition, as citizens were given the tools to challenge "official versions of events" (Greer \& McLaughlin, 2010). 
Although the Chinese state media's influence has been diluted, the government has made numerous attempts to regulate online speech in social media platforms (Ceron et al., 2016). Also, state-run media such as The People's Daily, by releasing information through social media platforms, allows for instant interaction and convenience while maintaining its authority and credibility (Li, 2015). Despite the long-standing propaganda strategy on family planning policy in China ( $\mathrm{Li}, 2017$; Xiong, 2017; Zhang \& An, 2018), little is known about agenda-setting patterns in social media platforms (Lu \& Zheng, 2017; Wang \& Song, 2019).

Weibo can be a rich source of social media public opinion research with respect to China's family planning policy. Lu and Zheng (2017) conducted a study to identify public concerns regarding the two-child policy, using Weibo microblogs, and found that the vast majority of users cared about education, health care, and the economy. Yang et al. (2017) analyzed how female users on Weibo discussed the universal two-child policy, finding that Chinese women were most concerned about the financial burden of supporting young children and the elderly at the same time. Wang and Song (2019) studied Weibo posts on the one-child policy, comparing different demographic and socioeconomic groups.

\section{DATA AND METHODOLOGY}

This article employs a text mining method to retrieve data from Weibo, using $\mathrm{R}$ packages. Weibo's huge user base and large number of active users offers representativeness and generalizability. We collected The People's Daily's official Weibo account social media posts on the family planning policy as well as subsequent threads of comments from January 2013 to October 2019. We searched for keywords such as: “二孩” (second-child), “二胎” (secondbaby) and “生育” (birth), retrieving 90 posts with 178,892 subsequent threads of comments.

The number of harvested comments was lower than it first appeared because of Weibo's filtering functionality; also, the data crawling strategy based on the Weibo API is restricted by the server limit. While censorship limits available data as well, family planning policy has been one of the least politically controversial policy domains on Weibo, and the proportion of deleted user posts is relatively low. After filtering the invalid, repeated, or incomplete observations, we included 74,233 comments in our analysis, with more than 4 million words. The obtained data included every comment's text content as well as the commenter's user ID and gender information.

The first step of natural language processing included word segmentation, data cleaning, and weight calculation, employing Python scripts and supplemented by manual correction. At the stage of word segmentation, we applied jieba ${ }^{1}$, a Chinese word segmentation tool in Python-which discerns the maximum probability path and searches for the most probable combination based on the word frequency (Chen et al., 2018; Xiao et al., 2016). The Jieba cannot fully recognize some typical Chinese terms, such as “卫计委” (short for "National Health and Family Planning Commission of China"), or its successor “卫健委” (short for "National Health Commission of the People's Republic of China"). This entailed a cleaning process in which we converted Chinese characters, eliminated punctuation, and removed stopping words. For the weight calculation, we used the Term Frequency-Inverse Document Frequency (TF-IDF) method. We used Sklearn ${ }^{2}$ of Python libraries to import CountVectorizer and Tfidf Transformer for the calculation of TF-IDF.

As a part of computer-assisted content analysis, the text mining data collected from Weibo was summarized into latent topics, extracted through the application of Latent Dirichlet Allocation (LDA) modeling, using Python libraries, and inferred topics from documents using a "bag-of-words" approach with a generative probabilistic model (Barberá et al., 2019). LDA is a three-tiered (document-topic-word) Bayesian model in which each data set is a mixed set of unknown topics, and each topic is modeled as a mixed probability distribution (Blei, 2012; 
Wang, 2018). The LDA analysis generates the probability that a word belongs to a topic, helping to sort according to probability scores.

To identify and visualize the structure of public opinion, we applied the semantic network analysis method, based on recognizing frequencies and co-occurrences of words in a text, thereby identifying content meaning (De Graaf \& Van Der Vossen, 2013). Co-occurrence refers to the relationship between two nodes as measured by "semantic distance" (Shi \& Wang, 2017, p. 20). While the LDA modeling results described the trend of latent topics mainly based on frequencies, the semantic network analysis focused on "bundles" of information.

To analyze agenda-setting patterns in our social media data, we applied correlation analysis to the latent topics obtained from LDA analysis (as rank-order variables). Early studies of agenda setting applied manual coding to summarize news coverage, and survey methods to obtain public opinions: correlation analysis has been dominantly used to assess the agenda-setting effect. Although social media data is now available online and text can be machine-coded, correlation analysis is still widely applied for testing the agenda-setting hypothesis through similarity of issues (Conway et al., 2015; Su \& Borah, 2019; Wanta \& Hu, 1994; Winter \& Eyal, 1981). To estimate the agenda-setting effect between The People's Daily's Weibo posts and public comments, we selected topic attention congruence as the main criteria. Based on previous studies, this study calculated Spearman's rho ( $\rho)$ based on the topics' distribution (Liu \& Wang, 2019; Rogstad, 2016; Vargo \& Guo, 2017). Spearman's rank-order correlation coefficient is a nonparametric measure, which is suitable for our ranked variables.

The People's Daily posts, collected in sequential order by date, were denoted as "post $(t)$ " and individual Weibo users' comments on that post as "comments $(t)$ "; the subsequent entries were denoted as "post $(t+1)$ " and "comments $(t+1)$," respectively. There were five correlation pairs between the post and the comments: the synchronous correlations between "post $(t)$ " and "comments $(t)$," the (auto)correlations between "post $(t)$ " and "post $(t+1)$," (auto)correlation between "comments $(t)$ " and "comment $(t+1)$," correlations of "comments (t)" and "post $(t+1)$," and correlation between "post $(t)$ " and "comments $(t+1)$." We used the latent topics from LDA modeling to see whether the sample topics emerge (or are correlated) in the pairs.

Different pairings of post and comments showed different directions of agenda-setting influence. For example, a correlation between the latent topics in post $(t)$ and those in comments $(t+1)$ may illustrate the agenda-setting impact ("media tell people" what to think about), while the correlation between comments $(t)$ and post $(t+1)$ could indicate a reverse agenda-setting impact ("people tell the media" what to write about).

\section{FINDINGS}

Due to the relatively long time span of this study, we divided the data into 14 six-month periods, from 2013 to 2019 . Figure 1 presents the total account of posts and the average number of comments and "reposts" within each 6-month period. At a glance, we saw that certain posts attracted more public attention than others, while the number of comments tended to increase steadily over time. For example, The People's Daily posted more often about family planning policy in the second half of 2015 and the first half of 2016, when the two-child policy came into effect, but did not attract many comments or reposts. However, posts in 2018 and 2019 seemed to produce many more comments and reposts.

Each bar in Figure 2 presents the female-male ratio of the comments on each post, showing gender-based selective attention to different posts. On average, commenters were $44.4 \%$ (male) to $55.6 \%$ (female). Weibo has more male users (57\%) (Weibo Data Center, 2018), but our analysis found that female users were more likely to comment on the two-child 


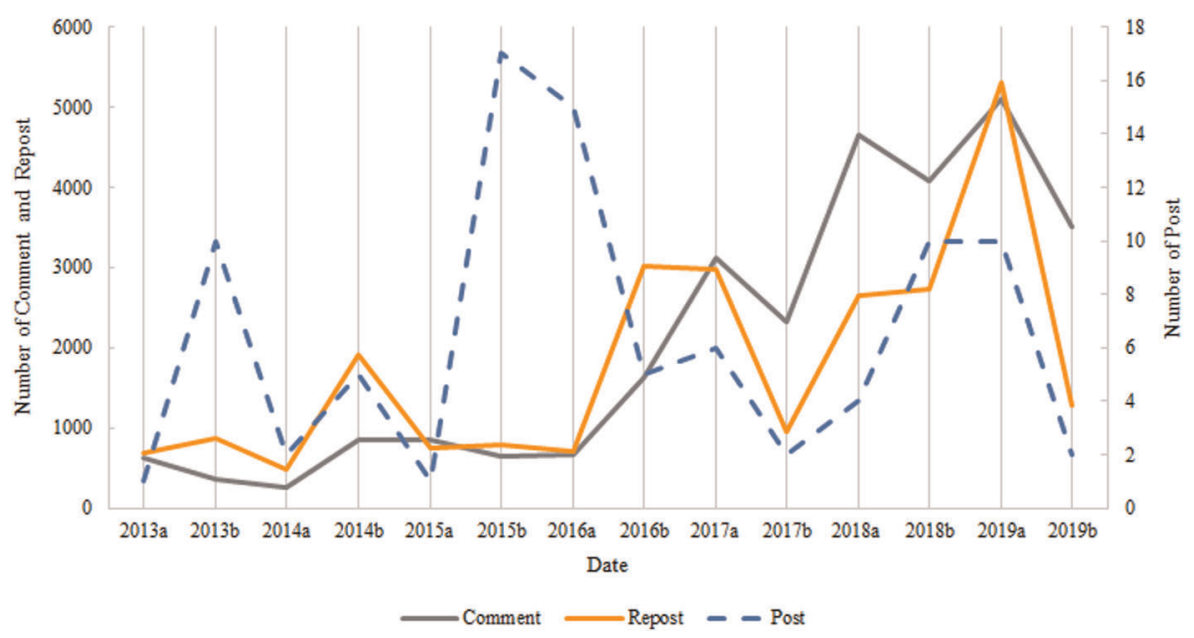

FIGURE 1 The number of posts, comments, and reposts. Note: In the horizontal axis, "a" represents the first half of the year while "b" represents the second half of the year

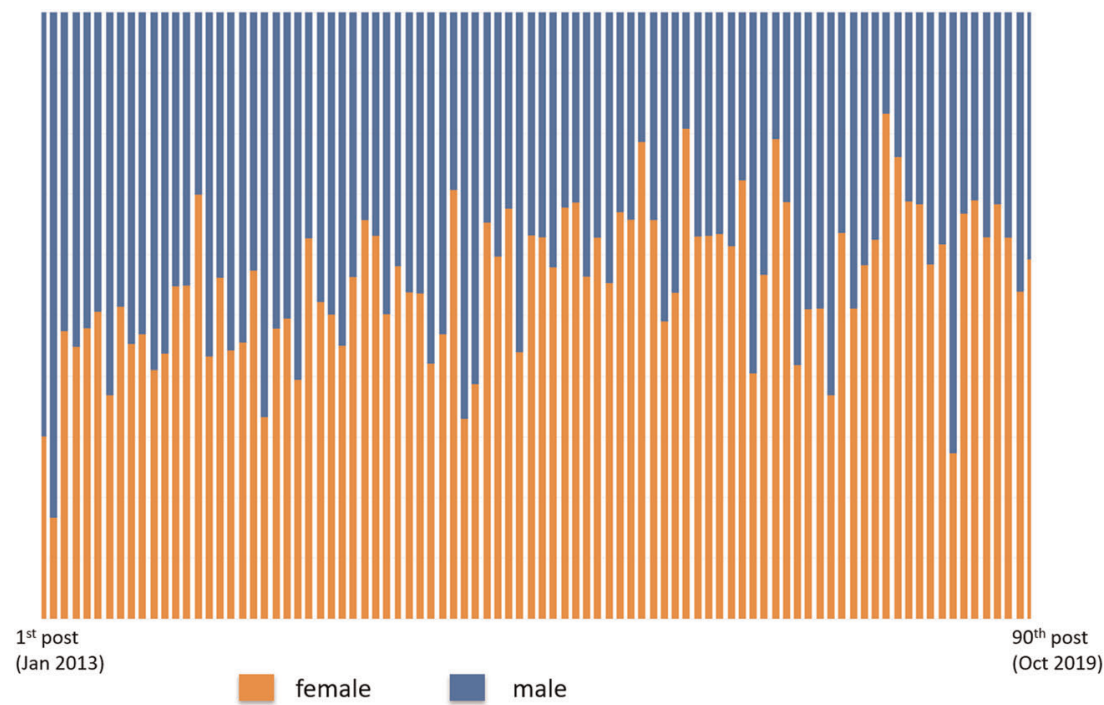

FIG URE 2 Gender ratio of user comments in People's Daily Weibo posts on one-child policy. Note: Each bar is the ration of comments in each post

policy, at times dominating certain posts. Table 1 shows the difference in keywords used between female and male commenters: we found that males preferred words such as "penalty," "housing price," and "law," while females chose words such as "husband," "mother-inlaw," and "baby."

As our LDA topic modeling $(k=20)$ provides a rough aggregation of latent topics, we categorized them into "topic sets" by employing brainstorming methods suggested by Zhang et al. (2015). To avoid a potential source of bias in this categorization, we reflected key previous studies on Chinese family planning policy in the sorting process (Lu \& Zheng, 2017; Wang \& Song, 2019; Yang et al., 2017). 
TABLE 1 Comparison of keywords between male and female

\begin{tabular}{llll} 
Male user's keywords & Frequency & Female user's keywords & Frequency \\
\hline People & 429 & Painless & 867 \\
\hline Penalty & 305 & Husband & 799 \\
\hline Housing prices & 295 & Mother-in-law & 664 \\
\hline House & 279 & Mother & 624 \\
\hline Law & 273 & Cute & 504 \\
\hline Civil servants & 233 & Baby & 488 \\
\hline Medical treatment & 223 & Younger Brother & 450 \\
\hline Give unscheduled birth & 223 & Girls & 437 \\
\hline Ordinary people & 218 & Puerpera & 403 \\
\hline Introduce & 216 & Epidural & 396 \\
Compulsive & 205 & Effort & 363 \\
Department & 195 & Elder Brother & 363 \\
\hline Development & 194 & Patriarchy & 362 \\
\hline Reality & 186 & Interview & 356 \\
\hline Expert & 183 & Condition & 347 \\
\hline Labor law & 179 & Equality & 321 \\
\hline Family planning commission & 170 & Fair & 310 \\
\hline Sack & 166 & Understand & 305 \\
\hline Couple & 164 & Sexism & 285 \\
\hline Contract & 160 & Generalize & 279 \\
\hline Women's rights & 160 & Bachelor & 272 \\
\hline Human & 154 & Age & \\
\hline$\ldots$ & & $\ldots$ & \\
\hline
\end{tabular}

Table 2 shows the resulting classifications of topics with LDA probability score, as follows: (i) words such as "working mom," "maternity leave," "equality," "sexism," and "employee" were categorized into the "Woman's Right to Work" topic set; (ii) words such as "patriarchy," "mother-in-law," "parents," and "rural" were categorized into "Family Culture and Tradition"; (iii) words such as "household" (translation of hukou, meaning registered permanent residence), "penalty," and "duty" were categorized into "Law and Regulation"; and (iv) words such as "costs of housing," "health care," and "education" were categorized into "Social Welfare and Wellbeing."

Audience fragmentation must be considered in social media public opinion research (Barberá et al., 2019; L. Chen et al., 2019; Feezell, 2018). Since our descriptive statistics showed different interests between genders on this family planning policy agenda, we analyzed gender differences for the chance that certain latent topic sets were mentioned in comments. Figure 3 presents these differences over time: a higher probability indicates a higher chance of emergence. The "Law and Regulation" topic set was more likely to emerge in male users' comments consistently over time, while "Women's Right to Work" was more 
TABLE 2 Topic classification and LDA probability score

\begin{tabular}{|c|c|c|}
\hline Topic sets & LDA probability & Corresponding latent topics \\
\hline Women's right to work & 0.2505 & $\begin{array}{l}\text { Topic } 7 \text { (Interview, Recruitment, Opportunity, Two-child); Topic } 17 \\
\text { (Graduate, Girls, Equality, Woman's Rights); Topic } 8 \text { (Female, } \\
\text { Health, Birth, Rights); Topic } 18 \text { (Working Mom/Woman, } \\
\text { Pregnancy, Sack, Contract); Topic } 10 \text { (Maternity Leave, Salary, } \\
\text { Marriage Leave, Subsidy); Topic } 19 \text { (Rumor, Human Rights, } \\
\text { Sexism, Security); Topic } 11 \text { (Enterprise, Company, } \\
\text { Employee, Cost) }\end{array}$ \\
\hline $\begin{array}{l}\text { Family culture and } \\
\text { tradition }\end{array}$ & 0.2924 & $\begin{array}{l}\text { Topic } 1 \text { (Mother, Family, Influence, Husband); Topic } 9 \text { (Cute, } \\
\text { Baby, Name, Elder Brother); Topic } 3 \text { (Patriarchy, Inheritance, } \\
\text { Rural, Dowry); Topic } 13 \text { (Family, Parents, Discussion, } \\
\text { Selfishness); Topic } 4 \text { (Mother-in-law, Situation, Dispute, } \\
\text { Two-child) }\end{array}$ \\
\hline Law and regulation & 0.2551 & $\begin{array}{l}\text { Topic } 2 \text { (People's Daily, Data, Survey, Propaganda); Topic } 14 \\
\text { (Society, Law, Duty, China); Topic } 5 \text { (Only Child, Policy, } \\
\text { Household, Penalty); Topic } 15 \text { (Policy, Ordinary People, Civil } \\
\text { Servants, Encouragement) }\end{array}$ \\
\hline $\begin{array}{l}\text { Social welfare and } \\
\text { wellbeing }\end{array}$ & 0.2018 & $\begin{array}{l}\text { Topic } 0 \text { (Child, Housing Prices, Medical Treatment, Education); } \\
\text { Topic } 12 \text { (Can't afford, Child, Pressure, Pension); Topic } 6 \\
\text { (Patriarchy, Shortage, Anesthetist, Hospital); Topic } 16 \text { (Time, } \\
\text { Job, Expert, Can't afford) }\end{array}$ \\
\hline
\end{tabular}

Note: Words in parentheses are examples included in the latent topic.

Women's Right to Work

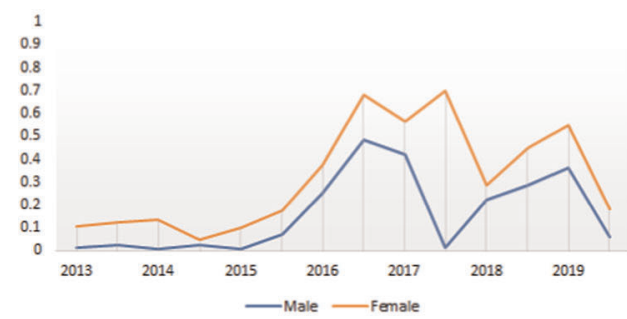

Law and Regulation

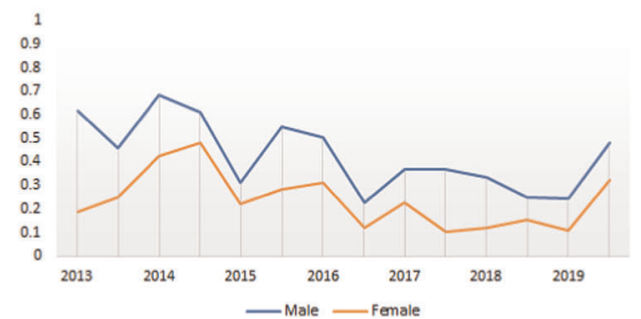

Family Culture and Tradition

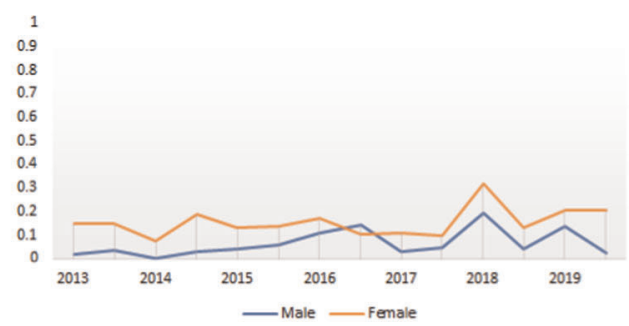

Social Welfare and Wellbeing

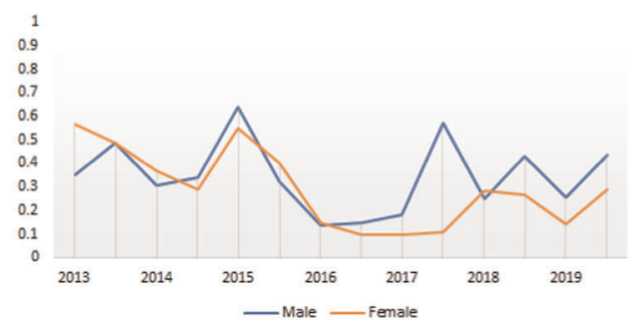

FIGURE 3 The probability of latent topic mention in Weibo comments by gender

likely to appear in female users' comments; this contrast was highest in the second half of 2017.

We analyzed the relationship between words through semantic network analysis, which provides a structure of links (edges) between words (nodes). As our data contained over 


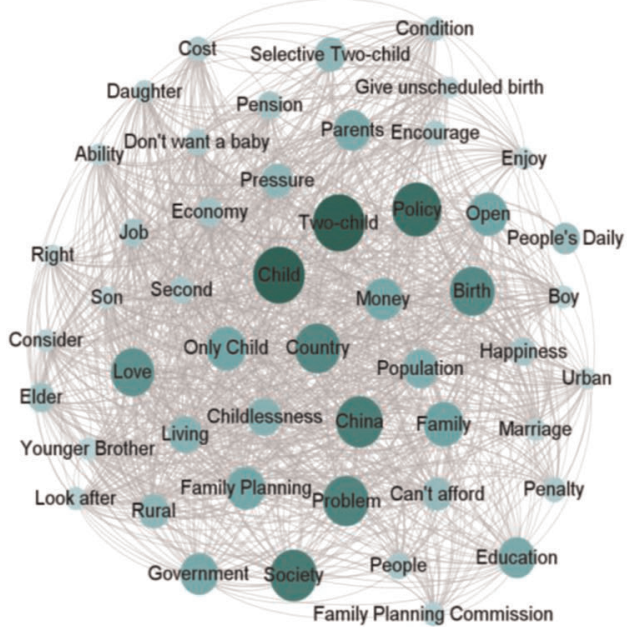

2013-2015

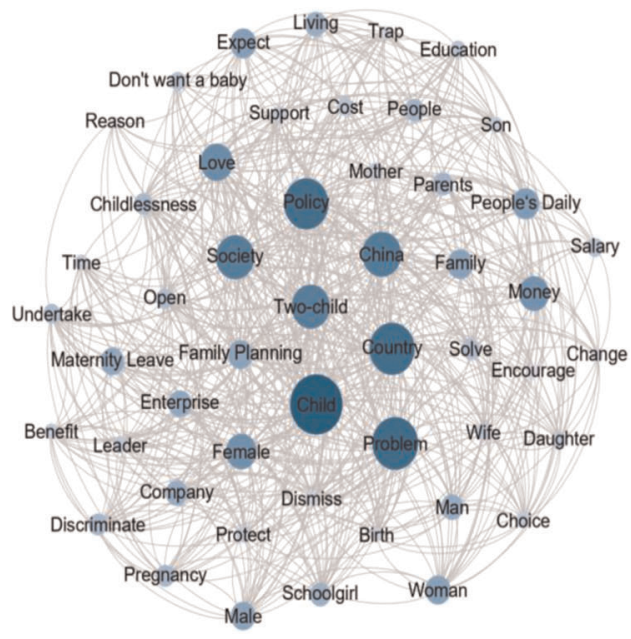

2016-2019

FIGURE 4 Network of the most-mentioned words in Weibo comments (on People's Daily Weibo post of two-child Policy). Note: The larger and darker nodes have a higher frequency

4 million words, we selected the top-50 highest network centrality words among user comments and coded the co-occurrent words as edges of the network. Figure 4 presents this network map in 2013-2015 (just after the two-child policy was formally announced) and in 2016-2019 (just after the policy came into effect).

Some words were central in both periods, such as "child," "two-child," "policy," "country," and "China," while others were more centrally located in one period over the other. For example, words such as "economy," "money," "pension," "pressure," and "population" were more centrally located in the 2013-2015 network map, with more connected (central) nodes, compared to that of 2016-2019, which saw more mentions of "mother," "support," "love," "wife," and "maternity leave." This seems to reflect changing priorities over time between the two periods.

The results of the Spearman rank-order correlation analysis in Table 3 show the degree to which an agenda-setting effect or a reverse agenda-setting effect appears in our data. A higher percentage means that the effect (or reverse effect) can be observed more often in the pairs, while higher correlation coefficients (Spearman's $\rho$ ) indicate that the commentpost pairs tend to mention more similar latent topics. The strongest association was observed between comments $(t)$ and comments $(t+1)$, with $63.3 \%$ of pairs showing statistically significant correlations and with Spearman's $\rho$ of 0.622 , which is quite high compared to previous studies in this field. This comment-to-comment association in latent topics may show how Weibo users set the agenda by impacting subsequent social media discussions. This comment-to-comment agenda setting could also indicate individual opinion influencers in family planning policy, who make certain issues more viral.

Comment-to-post (reverse) agenda setting is the central question of this article, and correlations of topic ranks between comments $(t)$ and post $(t+1)$ are statistically significant in just $14.6 \%$ of total pairs, with an average Spearman's $\rho$ of 0.522 . This means that we observed the reverse agenda-setting phenomenon in a limited number of pairs: the percentage of statistically significant correlations in the pairs is not high. Therefore, this study may reveal only a "partial" reverse agenda-setting effect.

Pairs of post $(t)$ and comments $(t+1)$ have statistically significant correlations of topics in $15.7 \%$ of the sample, with an average Spearman's $\rho$ of 0.547 . Overall, this post-to-comment 
TABLE 3 Correlation of latent topic attention between The People's Daily and the public

\begin{tabular}{lll} 
Comment-post pairs & $\%$ of statistically significant pairs & Average Spearman's $\rho$ \\
Comments $(t) \&$ post $(t+1)$ & 14.6 & 0.522 \\
\hline Post $(t) \&$ comments $(t+1)$ & 15.7 & 0.547 \\
Post $(t) \&$ post $(t+1)$ & 20.0 & 0.600 \\
Post $(t) \&$ comments $(t)$ & 34.4 & 0.533 \\
Comments $(t) \&$ comments $(t+1)$ & 63.3 & 0.622 \\
\hline
\end{tabular}

Note: The percentage refers to the significant pairs, and the average Spearman's $\rho$ means the average value of significant pairs' rank correlation coefficient.

agenda setting with time-lag is a lot weaker than pairs of post (t) and comments (t), in which $34.4 \%$ of pairs were statistically significant, with a Spearman's $\rho$ of 0.600 . This implies that the agenda-setting effect of The People's Daily's post does not last long. The frequency and magnitude of top-down agenda-setting effects observed in pairs of post $(t)$ and comments $(t+1)$ were not too different from reverse agenda-setting effects observed in pairs of comments $(\mathrm{t})$ and post $(\mathrm{t}+1)$-considering both analyses used the time-lag, we suggest that the comment-to-post (reserve) agenda-setting effect is not necessarily weaker than the post-to-comment agenda-setting effect.

\section{DISCUSSION}

The results presented in this article extend the research on agenda-setting between China's state-run media and the general public in the context of social media, focused on whofollows-whom questions (Harder et al., 2017). Our analyses showed that state-run media (The People's Daily) still maintained a certain role in top-down agenda setting on social media (Weibo), consistent with the conclusions in previous research (Z. Chen et al., 2019; Luo, 2014). We also observed limited, but existing (partial) reverse agenda setting initiated from individual Weibo comments to the state-run outlet.

Our findings echo previous research stating that the state-controlled mainstream media in China tends to avoid some core but sensitive matters, despite public concerns (Z. Chen et al., 2019; Su \& Xiao, 2020; Wu et al., 2013), in the supposed interests of societal stability (Fu et al., 2013). Some blocked or censored data in Weibo limited our data sample and analysis. For instance, comments discussing the burden of child-rearing and the possibility of maternity leave for men were strictly censored. Nevertheless, the proportion of deleted posts was relatively low.

We also identified a few cases of bottom-up agenda setting on social media. Our qualitative observations revealed that some opinion influencers led public concerns by commenting quickly and repeatedly. The state media was responsive to public concerns when the clamor became loud enough (Hassid, 2015). On maternal workplace issues, for example, we found viral individual user comments such as "female employees are required to apply for the pregnancy quota (i.e., maternity leave) one year in advance," "in principle, HR doesn't recruit women who have a child," and "the recruitment procedures shall not make any enquiries about female applicants' marital status": The People's Daily followed these concerns by posting related reports about working mothers.

Such viral concerns expose the policy's flaws, impact the direction of the original agenda, and open policy windows (Wang \& Wu, 2019). Under the premise of downplaying the role of online censorship in China, the cross-fertilization between The People's Daily and Weibo yields much more discussion space for less sensitive political and social issues. Social 
media's ability to instantly expose a post to a large number of users could even extend the agenda-setting power of state media. In short, when the state media feel in control of messaging on an issue, they tolerate, and sometimes even encourage, criticism and comment (Hassid, 2012). As such, this supposed loosening of public expression may be an effective tool to satisfy and mollify the masses (Fu et al., 2013).

However, public opinion's influence on state media's response could be conditional or temporary. That being said, the reverse agenda-setting effect could be contingent depending on policy type, or stage in the policy cycle. In our qualitative assessments, we found that The People's Daily exerted more efforts to respond to individuals' user comments in follow-up Weibo posts in 2016. On particular days that year, The People's Daily posted several times a day on trending topics related to the two-child policy. The newspaper may have been more inclined to engage with and address public concerns on social media during the early days of the policy's implementation.

Gender differences constitute an important observation in our study, especially when it comes to audience fragmentation and increased selectivity in today's social media environment. This may reflect uneven policy impacts or differing priorities by gender. More comments were derived from female users (55.6\%), deviating from the conventional wisdom that political issues are traditionally a male domain (Hassid, 2015; Stockmann \& Luo, 2015; Wang \& Song, 2019). Beyond the simple relevance of fertility policy to females, this finding suggests females' increased interest in public affairs. Our results showed that females commented on topics related to family, culture, and tradition or women's right to work, while male users tended to discuss regulation and legislation. This gendered dynamic calls for more research on how gender differences affect policy development and implementation, by, for example, balancing the gender ratio of legislators and considering multi-stakeholder interests.

\section{CONCLUSION}

When the one-child policy was relaxed, the debate on social media reflected nation-wide interest. People of different genders, ages, regions, and educational backgrounds engaged in the discussion and shaped the public agenda. Our social media text mining analysis of more than 74,000 Weibo user comments on The People's Daily's media coverage over 6 years showed four latent topic sets: women's right to work, family, culture, and tradition, law and regulation, and social welfare and wellbeing. Our analysis demonstrated instances of the reversed agenda-setting effect, although only partially. Chinese mass media may not be as marginalized in the social media environment as some scholars suggest, although its ability to reach the public could be moderated by social media algorithms, social network composition, and usage patterns.

In authoritarian regimes, the primary concern is whether social media increases freedom and promotes the democratic public environment or is manipulated by the state to strengthen restraint and monitoring (Nip \& Fu, 2016; Stockmann \& Luo, 2015). By observing the changes in family planning policy, this study offers a middle-ground explanation: after continual negotiation, the two sides mutually transformed. On the Weibo platform, the public regards the state media as their main channel for voicing discontent and increasing influence. In turn, the state uses it as a tool to show a certain receptivity and quasi-democratic quality, to mitigate social contention and enhance its legitimacy (Meng et al., 2017).

As this study is still exploratory in nature, future research should address some of its limitations. While Weibo users are not synonymous with China's population as a whole, they can be conceived as a representation of a comparatively extensive subset. However, it is still important to observe the differences between real-world interactions and those on social media, as social media data is often distorted because the users make decisions based on recommendations suggested by algorithms (Löfgren \& Webster, 2020). 
Furthermore, the relatively limited volume of data we collected does not capture the full social media opinion. This, and content censorship, can be addressed by future studies using methods that consider those systematic truncations of data. In addition, more longitudinal studies could uncover long-standing agenda-setting impacts in either direction. Future research may also need to develop more sophisticated testing methods and topic modeling, such as hashtag-pooling or deep learning-based models, to capture the multidirectional effect of agenda-setting in Chinese social media.

\section{ACKNOWLEDGMENT}

Wen Deng's contribution to this article is partially supported by the Fundamental Research Funds for the Central Universities, grant number 2015AE002.

\section{ORCID}

Wen Deng (D) https://orcid.org/0000-0002-6221-4608

Jia-Huey Hsu (D) http://orcid.org/0000-0002-1785-5406

Karl Löfgren (D) http://orcid.org/0000-0002-9303-0895

Wonhyuk Cho (D) http://orcid.org/0000-0001-7607-6480

\section{REFERENCES}

Allen, B., Tamindael, L. E., Bickerton, S. H., \& Cho, W. (2020). Does citizen coproduction lead to better urban services in smart cities projects? An empirical study on e-participation in a mobile big data platform. Government Information Quarterly, 37(1), 101412. https://doi.org/10.1016/j.giq.2019.101412

Aragón, P., Gómez, V., \& Kaltenbrunner, A. (2017). Detecting platform effects in online discussions. Policy \& Internet, 9(4), 420-443. https://doi.org/10.1002/poi3.158

Barberá, P., Casas, A., Nagler, J., Egan, P. J., Bonneau, R., Jost, J. T., \& Tucker, J. A. (2019). Who leads? Who follows? Measuring issue attention and agenda setting by legislators and the mass public using social media data. American Political Science Review, 113(4), 883-901. https://doi.org/10.1017/ s0003055419000352

Blei, D. M. (2012). Probabilistic topic models. Communications of the ACM, 55(4), 77-84. https://doi.org/10.1145/ 2133806.2133826

Cai, Y. (2013). China's new demographic reality: Learning from the 2010 census. Population and Development Review, 39(3), 371-396. https://doi.org/10.1111/j.1728-4457.2013.00608.x

Ceron, A., Curini, L., \& lacus, S. M. (2016). First- and second-level agenda setting in the Twittersphere: An application to the Italian political debate. Journal of Information Technology \& Politics, 13(2), 159-174. https:// doi.org/10.1080/19331681.2016.1160266

Chaffee, S. H., \& Metzger, M. J. (2001). The end of mass communication? Mass Communication and Society, 4(4), 365-379. https://doi.org/10.1207/s15327825mcs0404_3

Chan, A. (2007). Guiding public opinion through social agenda-setting: China's media policy since the 1990s. Journal of Contemporary China, 16(53), 547-559. https://doi.org/10.1080/10670560701562267

Chen, J., Becken, S., \& Stantic, B. (2018). Sentiment analytics of Chinese social media posts. In The 8th International Conference on Web Intelligence, Mining and Semantics, Novi Sad Serbia, 1-7. https://doi.org/ $10.1145 / 3227609.3227680$

Chen, L., Shi, J., Guo, Y., Wang, P., \& Li, Y. (2019). Agenda-setting on traditional vs social media. Internet Research, 29(4), 688-703. https://doi.org/10.1108/intr-08-2017-0315

Chen, Z., Su, C. C., \& Chen, A. (2019). Top-down or bottom-up? A network agenda-setting study of Chinese nationalism on social media. Journal of Broadcasting \& Electronic Media, 63(3), 512-533. https://doi.org/10. $1080 / 08838151.2019 .1653104$

Cho, W., \& Melisa, W. D. (2021). Citizen coproduction and social media communication: Delivering a municipal government's urban services through digital participation. Administrative Sciences, 11(2), 59. https://doi.org/ 10.3390/admsci11020059

Conover, M. D., Gonçalves, B., Ratkiewicz, J., Flammini, A., \& Menczer, F. (2011). Predicting the political alignment of Twitter users. In 2011 IEEE Third International Conference on Social Computing, Boston, 192-199. https:// doi.org/10.1109/PASSAT/SocialCom.2011.34

Conway, B. A., Kenski, K., \& Wang, D. (2015). The rise of Twitter in the political campaign: Searching for intermedia agenda-setting effects in the presidential primary. Journal of Computer-Mediated Communication, 20(4), 363-380. http://doi.org/10.1111/jcc4.12124 
de Graaf, R., \& van der Vossen, R. (2013). Bits versus brains in content analysis. Comparing the advantages and disadvantages of manual and automated methods for content analysis. Communications, 38(4), 433-443. https://doi.org/10.1515/commun-2013-0025

Ding, W., \& Zhang, Y. (2014). When a son is born: The impact of fertility patterns on family finance in rural China. China Economic Review, 30(9), 192-208. https://doi.org/10.1016/j.chieco.2014.06.008

Feeney, M. K., \& Porumbescu, G. (2020). The limits of social media for public administration research and practice. Public Administration Review. https://doi.org/10.1111/puar.13276

Feezell, J. T. (2018). Agenda setting through social media: The importance of incidental news exposure and social filtering in the digital era. Political Research Quarterly, 71(2), 482-494. https://doi.org/10.1177/1065912917744895

Fu, K. W., Chan, C. H., \& Chau, M. (2013). Assessing censorship on microblogs in China: Discriminatory keyword analysis and the real-name registration policy. IEEE Internet Computing, 17(3), 42-50. https://doi.org/10.1109/mic.2013.28

Gong, W., Xu, D., \& Caine, E. D. (2016). Challenges arising from China's two-child policy. The Lancet, 387(10025), 1274. https://doi.org/10.1016/s0140-6736(16)30020-4

Greer, C., \& McLaughlin, E. (2010). We predict a riot?: Public order policing, new media environments and the rise of the citizen journalist. British Journal of Criminology, 50(6), 1041-1059. https://doi.org/10.1093/bjc/azq039

Groshek, J., \& Groshek, M. C. (2013). Agenda trending: Reciprocity and the predictive capacity of social networking sites in intermedia agenda setting across topics over time. Media and Communication, 1(1), 15-27. https:// doi.org/10.17645/mac.v1i1.71

Grzywińska, I., \& Batorski, D. B. (2016). How the emergence of social networking sites challenges agenda-setting theory. Konteksty Spoteczne, 1(7), 19-32.

Gu, Q. (2014). Sina Weibo: A mutual communication apparatus between the Chinese government and Chinese citizens. China Media Research, 10(2), 72-85.

Guntermann, E., \& Persson, M. (2021). Issue voting and government responsiveness to policy preferences. Political Behavior. https://doi.org/10.1007/s11109-021-09716-8

Guo, L. (2019). Media agenda diversity and intermedia agenda setting in a controlled media environment: A computational analysis of china's online news. Journalism Studies, 20(16), 2460-2477. https://doi.org/10. 1080/1461670x.2019.1601029

Guo, L., \& McCombs, M. (2015). The power of information networks: New directions for agenda setting. Routledge.

Harder, R. A., Sevenans, J., \& Van Aelst, P. (2017). Intermedia agenda setting in the social media age: How traditional players dominate the news agenda in election times. The International Journal of Press/Politics, 22(3), 275-293. https://doi.org/10.1177/1940161217704969

Hassid, J. (2012). Safety valve or pressure cooker? Blogs in Chinese political life. Journal of Communication, 62(2), 212-230. https://doi.org/10.1111/j.1460-2466.2012.01634.x

Hassid, J. (2015). Chinese government responsiveness to internet opinion: Promising but dangerous. Journal of Current Chinese Affairs, 44(2), 39-68. https://doi.org/10.2139/ssrn.2308813

Hassid, J., \& Sun, W. (2015). Stability maintenance and Chinese media: Beyond political communication? Journal of Current Chinese Affairs, 44(2), 3-15. https://doi.org/10.1177/186810261504400201

Hesketh, T., \& Zhu, W. X. (1997). Health in China: The one child family policy: The good, the bad, and the ugly. BMJ, 314(7095), 1685. https://doi.org/10.1136/bmj.314.7095.1685

Ho, A. T. K., \& Cho, W. (2017). Government communication effectiveness and satisfaction with police performance: A large-scale survey study. Public Administration Review, 77(2), 228-239. https://doi.org/10.1111/puar.12563

Honey, C., \& Herring, S. C. (2009). Beyond microblogging: Conversation and collaboration via Twitter. In 42nd Hawaii International Conference on System Sciences, Waikoloa, 1-10. https://doi.org/10.1109/HICSS.2009.89

Huang, W. (2017). How does the one child policy impact social and economic outcomes? [online] https://wol.iza. org. Retrieved from https://wol.iza.org/articles/how-does-the-one-child-policy-impact-social-and-economicoutcomes/long

Hutchinson, J. (2021). Micro-platformization for digital activism on social media. Information, Communication \& Society, 24(1), 35-51. https://doi.org/10.1080/1369118x.2019.1629612

Im, T., Cho, W., Porumbescu, G., \& Park, J. (2014). Internet, trust in government, and citizen compliance. Journal of Public Administration Research and Theory, 24(3), 741-763. https://doi.org/10.1093/jopart/mus037

Im, T., Lee, H., Cho, W., \& Campbell, J. W. (2013). Citizen preference and resource allocation: The case for participatory budgeting in Seoul. Local Government Studies, 40(1), 102-120. https://doi.org/10.1080/ 03003930.2013 .812963

Janowitz, M. (1975). Professional models in journalism: The gatekeeper and the advocate. Journalism Quarterly, 52(4), 618-626. https://doi.org/10.1177/107769907505200402

Jiang, M., \& Fu, K. W. (2018). Chinese social media and big data: Big data, big brother, big profit? Policy \& Internet 10(4), 372-392. https://doi.org/10.1002/poi3.187

Jiang, Y. (2014). 'Reversed agenda-setting effects' in China Case studies of Weibo trending topics and the effects on state-owned media in China. Journal of International Communication, 20(2), 168-183. https://doi.org/10. 1080/13216597.2014.908785 
Kim, M.-H., Cho, W., Choi, H., \& Hur, J. Y. (2020). Assessing the South Korean model of emergency management during the COVID-19 pandemic. Asian Studies Review, 44(4), 567-578. https://doi.org/10. 1080/10357823.2020.1779658

Kim, M.-H., Li, H., Holzer, M., \& Zhang, M. (2019). Public administration research in mainland China: A systematic review of Chinese public administration in English language journals (1996-2016). International Journal of Public Administration, 42(9), 753-764. https://doi.org/10.1080/01900692.2018.1506936

King, G., Pan, J., \& Roberts, M. E. (2013). How censorship in China allows government criticism but silences collective expression. American Political Science Review, 107(2), 326-343. https://doi.org/10.1017/s0003055413000014

Kreiss, D., \& McGregor, S. C. (2018). Technology firms shape political communication: The work of Microsoft, Facebook, Twitter, and Google with campaigns during the 2016 U.S. presidential cycle. Political Communication, 35(2), 155-177. https://doi.org/10.1080/10584609.2017.1364814

$\mathrm{Li}, \mathrm{X}$. (2015). The characteristics of major natural disasters reported by People's Daily's official Microblog take Ya 'an earthquake and Ludian earthquake as examples for statistical analysis. Southeast Communication, (8), 98-100.

Li, X., Xuan, Q., \& Kluver, R. (2003). Who is setting the Chinese agenda?: The impact of online chatrooms on party presses in China. In K. C. Ho, C.C. Randy, \& K. Yang (Eds.), Asia.Com: Asia encounters the internet (pp. 161-76). Routledge.

$\mathrm{Li}, \mathrm{Y}$. (2017). The Policy communication of "universal two-child policy: Ways and Problems of Identity Construction. Journal of News Research, 8(18), 45-47.

Lin, W. Y., \& Zhang, X. (2020). The role of digital media in China: Participation in an unlikely place. In William H. Dutton (Ed.), A research agenda for digital politics. Edward Elgar Publishing.

Lippmann, W. (1946). Public opinion. Transaction Publishers.

Liu, Y., \& Wang, Y. (2019). The agenda-setting effect on medical issues: How newspaper affects public opinion on social media. Journalism Research, 9, 119-120.

Löfgren, K., Macaulay, M., Berman, E., \& Plimmer, G. (2018). Expectations, trust, and 'no surprises': Perceptions of autonomy in New Zealand crown entities. Australian Journal of Public Administration, 77(4), 672-684. https:// doi.org/10.1111/1467-8500.12305

Löfgren, K., \& Webster, C. W. R. (2020). The value of Big Data in government: The case of 'smart cities'. Big Data \& Society, 7(1), 2053951720912775. https://doi.org/10.1177/2053951720912775

Lu, Y., \& Zheng, M. (2017). Web topic analysis of the two-child policy in China. Procedia Computer Science, 107, 97-102. https://doi.org/10.1016/j.procs.2017.03.063

Luo, Y. (2014). The Internet and agenda setting in China: The influence of online public opinion on media coverage and government policy. International Journal of Communication, 8, 1289-1312.

McCombs, M. (2018). Setting the agenda: Mass media and public opinion. John Wiley \& Sons.

McCombs, M. E., \& Shaw, D. L. (1972). The agenda-setting function of mass media. Public Opinion Quarterly, 36(2), 176-187. https://doi.org/10.1086/267990

Meng, T., Pan, J., \& Yang, P. (2017). Conditional receptivity to citizen participation: Evidence from a survey experiment in China. Comparative Political Studies, 50(4), 399-433. https://doi.org/10.1177/0010414014556212

Nan, Z. (2003). The focus of improving news reporting is to keep close contact with the people. The Chinese Journalist, 3, 6-10.

Nip, J. Y. M., \& Fu, K. W. (2016). Challenging official propaganda? Public opinion leaders on Sina Weibo. The China Quarterly, 225, 122-144.

Pan, Z. (2000). Improving reform activities: The changing reality of journalistic practices in China. In C.-C. Lee (Ed.), Power, money, and media: Communication patterns and bureaucratic control in cultural China (pp. 68-111). Northweatwen University Press.

Qin, B., Strömberg, D., \& Wu, Y. (2017). Why does China allow freer social media? Protests versus surveillance and propaganda. Journal of Economic Perspectives, 31(1), 117-140. https://doi.org/10.1257/jep.31.1.117

Roberts, M., Wanta, W., \& Dzwo, T.-H. (2002). Agenda setting and issue salience online. Communication Research, 29(4), 452-465. https://doi.org/10.1177/0093650202029004004

Rogstad, I. (2016). Is Twitter just rehashing? Intermedia agenda setting between Twitter and mainstream media. Journal of Information Technology \& Politics, 13(2), 142-158. https://doi.org/10.1080/19331681.2016. 1160263

Sagarik, D., Chansukree, P., Cho, W., \& Berman, E. (2018). E-government 4.0 in Thailand: The role of central agencies. Information Polity, 23(3), 343-353. https://doi.org/10.3233/ip-180006

Shaw, D. L. (2004). Create a papyrus type society. Journal of International Communication, 4, 10-11.

Shaw, D. L. (2006). Vertical versus horizontal media: Using agenda-setting and audience agenda-melding to create public information strategies in the emerging papyrus society. Military Review, 86(6), 13.

Shi, A., \& Wang, P. (2017). Agenda-Setting Theory in the last 50 years: Origins, development and prospects for the future. Journalism \& Communication, 24(10), 13-28.

Stockmann, D., \& Luo, T. (2015). Authoritarianism2.0: Social media and political discussion in China [online] http:// www.ssrn.com/index.cfm/en/. Retrieved from https://ssrn.com/abstract=2650341 
Su, Y., \& Xiao, X. (2020). From WeChat to 'We set': Exploring the intermedia agenda-setting effects across WeChat public accounts, party newspaper and metropolitan newspapers in China. Chinese Journal of Communication, 1-19. https://doi.org/10.1080/17544750.2020.1839777

$\mathrm{Su}, \mathrm{Y}$., \& Borah, P. (2019). Who is the agenda setter? Examining the intermedia agenda-setting effect between Twitter and newspapers. Journal of Information Technology \& Politics, 16(3), 236-249. https://doi.org/10. 1080/19331681.2019.1641451

Sun, L., \& Zhang, L. (2015). Construction of new mainstream media under condition of media convergence. Chongqing Social Sciences, (1), 80-86.

Vargo, C. J., \& Guo, L. (2017). Networks, big data, and intermedia agenda setting: An analysis of traditional, partisan, and emerging online U.S. news. Journalism \& Mass Communication Quarterly, 94(4), 1031-1055. https://doi.org/10.1177/1077699016679976

Wang, G., \& Wu, H. (2019). From pressure-response to consensus-building: Focus events triggering mechanism in policy agenda setting-a qualitative comparative analysis based on 54 focus events. Journal of Public Management, 16(4), 36-47.

Wang, Q. (2015). Shuttling between politics and entertainment: Interplay between the media and media users during China's Red Cross scandal. The Journal of International Communication, 21(2), 241-256. https://doi. org/10.1080/13216597.2015.1052530

Wang, S., \& Song, Y. (2019). Chinese online public opinions on the Two-Child Policy. Online Information Review, 43(3), 387-403. https://doi.org/10.1108/oir-07-2017-0217

Wang, Y., \& Chen, C. (2016). Governments' crisis management and image construction in the era of social media: A case study of the Tianjin 812 explosion accident. Journalism \& Communication, 23(7), 47-59.

Wang, Z. (2018). Extracting latent topics from user reviews using online LDA. In the 2018 International Conference on Information Technology and Management Engineering, August 26-27, Beijing. https://doi.org/10.2991/ icitme-18.2018.41

Wanta, W., \& Hu, Y.-W. (1994). Time-lag differences in the agenda-setting process: An examination of five news media. International Journal of Public Opinion Research, 6(3), 225-240. https://doi.org/10.1093/ijpor/6.3.225

Watson, J. (2008). Media communication: An introduction to theory and process. Macmillan International Higher Education.

Weaver, D., McCombs, M., \& Shaw, D. L. (2004). Agenda-setting research: Issues, attributes, and influences. Handbook of Political Communication Research, 257-282.

Winter, J. P., \& Eyal, C. H. (1981). Agenda setting for the civil rights issue. Public Opinion Quarterly, 45(3), 376-383. https://doi.org/10.1086/268671

Wu, Y., Atkin, D., Lau, T. Y., Lin, C., \& Mou, Y. (2013). Agenda setting and micro-blog use: An analysis of the relationship between Sina Weibo and newspaper agendas in China. The Journal of Social Media in Society, 2(2), 8-25.

Xiao, K., Zhang, Z., \& Wu, J. (2016). Chinese text sentiment analysis based on improved Convolutional Neural Networks. In 2016 7th IEEE International Conference on Software Engineering and Service Science (ICSESS), Beijing. https://doi.org/10.1109/ICSESS.2016.7883216

Xiong, H. (2017). Research on the topic construction of "two-child family" by Chinese mass media. Modern Communication, 39(12), 63-65.

Xu, K., Liu, Y., Zhao, X., \& Dong, X. (2013). Trust them or not? A study on media credibility of newspapers accounts on Sina Weibo. [online] A Study on Media Credibility of Newspapers Accounts on Sina Weibo. https://doi.org/ $10.2139 / \mathrm{ssrn} .2258551$

Yang, F., Chen, X., \& Suo, Q. (2017). The discourse expression of women in social public topics from the perspective of Weibo. Modern Communication, 39(2), 139-143.

Yang, X., Chen, B. C., Maity, M., \& Ferrara, E. (2016). Social politics: Agenda setting and political communication on social media. In 8th International Conference on Social Informatics, November 11-14, Bellevue.

Zeng, Y., Zhang, X., \& Liu, L. (2017). From "selective two-child policy" to universal two-child policy: Will the payment crisis of China's pension system be solved? China Finance and Economic Review, 5(1), 14.

Zhang, L., \& An, R. (2018). Research on the External Communication Framework of China's two-child Policy. Modern Communication, 40(2), 165-167.

Zhang, Y., Li, B., \& Liu, C. (2015). Topic-oriented monitoring of public sentiment towards popular Weibo events: A case study on regular 'odd-even' vehicle restriction in Beijing. Journal of Chinese Information Processing, (5), 20.

How to cite this article: Deng, W., Hsu, J.-H., Löfgren, K., \& Cho, W. (2021). Who is leading China's family planning policy discourse in Weibo? A social media text mining analysis. Policy \& Internet, 1-17. https://doi.org/10.1002/poi3.264 